\title{
"I need to be there": British South Asian men's experiences of care and caring
}

\begin{abstract}
This article provides an insight into British South Asian men's experiences of care and caring. Care is gendered, however the ways in which care features in the lives of British Asian men is under-researched and demands attention, particularly given the changing demographics in the UK. The discussion draws on qualitative empirical research with a sample of British Asian men in their early thirties to early fifties. In depth interviews were conducted to consider roles and responsibilities within families and communities in relation to care, either as parents and/or as having ageing parents or grandparents. The findings give voice to British Asian men's experiences of care and enhance our understanding of care in the everyday and the complex and contested nature of contemporary British Asian masculinities. The findings challenge populist assumptions surrounding Asian men and provide an alternative insight into their experiences to highlight the centrality of care and caring in British Asian men's lives and to document that British Asian men do care. Whilst the stories of care are diverse, there is a strong sense that British Asian men value care, and place importance on being able to provide care and support to family.
\end{abstract}

\section{Keywords: Gender; masculinity; duty; responsibility; culture; family}

\section{Introduction}

This article considers qualitative research with British South Asian men to examine their experiences of care and caring in their everyday lives. Care is understood here to encompass care and caring relationships in a broad sense, for example in the context parenthood and care for ageing parents. Following from Philip, Rogers and Weller (2013, p.5), who draw on the theoretical contributions of Noddings (2003), care is understood as being a '...central, crucial and human practice' (emphasis in original), with a distinction drawn between the practice of 'caring for' and 'caring about'. More specifically, the empirical research which forms the basis for this article sought to examine how British South Asian men conceptualise care and consider how they construct their own stories of care. As part of this, the research considered the ways in which race, ethnicity, faith, and generation shape the discussions of 
care for Asian men, alongside a consideration of the gendered nature of care to consider care in the context of contemporary British Asian masculinities.

\section{Background}

My research journey into Asian masculinities has spanned over fifteen years and at the beginning in many ways mirrored my questions regarding my own identity. As a young British born Sikh man, navigating second generation identification with Sikhism and living and being bought up in Britain raised questions. Key theorists at this time, including Hall (1992), Brah (1996), and in relation to questions of masculinity; Mac an Ghaill (1994), encouraged a consideration of the performative nature of ethnicity and the ways in which ethnic identity is intersectional and experienced in and through other modalities of difference (such as race, gender, class, sexuality, McClintock, 1995). Black feminist literature, particularly looking at izzat (Wilson, 1978) was influential and developed my understanding of the gendered nature of Asian, and specifically Sikh masculinities in the plural (Gill, 2014).

Now the wider frame concerning what is more broadly defined as 'Asian masculinity' creates a different socio-political context. There is now a more overt and sustained pathologisation of 'Asian masculinity'(Kalra, 2009; Britton, 2018) and although aspects of this have been present since the Salman Rushdie affair (Britton, 2018) events from 9/11 onwards have led to further negative representations. The terrorist attacks of 7/7 in London and subsequent extremism, and a rising number of criminal convictions involving men of British Asian backgrounds 'grooming' and sexually abusing vulnerable white women and girls (Cockbain, 2013), shape a particular and negative portrayal of contemporary British Asian masculinity. Now, the 'Muslim' male has been made the most recognisable and the target of 'demonisation' (Bhattacharyya, 2008, p.87), creating very little space for alternative stories of Asian masculinity outside of the framework of deviance.

This research challenges such negative constructions of British Asian masculinity.. This is again informed partly through my own masculine identity at this point in my life course; for now I no longer identify with the young men who participated in my research into British Asian masculinities fifteen years ago, but rather my identity is shaped particularly in relation to spaces and practices of care; especially in relation to caring for ageing migrant parents whilst also being a father to young children. It is also apparent that care is central to current political debates and wider social concern across the UK and therefore demands our attention. The last decade has seen a substantial increase in the number of adults in their late eighties, 
and this number is expected to increase in the next decade. This is an age group with complex health and social care needs (Age UK, 2016) and it is predicted that there will be '...3.8 million Black and minority ethnic older people aged 65 and over and 2.8 million aged 70 and over' by 2051 in England and Wales (Lieversley, 2010, p. 5). This raises significant questions surrounding how best to provide care and support for an ageing BME population in the context of rising levels of austerity, and in turn raises questions in relation to those who provide such care outside of formal caring services and within the context of family, kin and community.

\section{Care in the context of British Asian masculinities}

Care and caring is multifaceted and gendered. It is evident that many aspects of caring are feminised and considered integral to femininity. Indeed, it remains the case that it is often women who are assigned the primary role and responsibility of caring within families and care continues to play a significant role in shaping their gendered identities (Lynch, 2007, 2009). According to recent data by the ONS (2016), 'women carry out an overallaverage of $60 \%$ more unpaid work than men' Whilst there are differences between and within ethnic groups in relation to care, caring responsibilities more often fall on female family members (Hoff, 2015) although this is not always the case, as care giving maybe shared in partnerships and families between men and women. Feminist theorists have argued for the need to recognise, value and legitimate care and care practices in women's lives, whilst also consider care and caring as a valid area of study outside the private and the personal (Philip et al., 2013; Lynch, 2007). Lynch (2009, p.411) makes clear that '[T]here are deep gender inequalities in the doing of care and love work...It is women's unwaged care and related domestic labour that frees men up to exercise control in the public sphere of politics, the economy and culture'. However, the ways in which care and caring relates to being a man and masculinity has comparatively received limited attention (Reynolds, 2013). Whilst there has been a recent development of research on the notion of 'caring masculinities' which recognises the importance of understanding care in the context of masculinity, and its relationship with gender equality (see for example, Elliott, 2016; Ruby and Scholz, 2018), there is a need for further research which considers this in the context of race and ethnicity. Questions remain regarding what needs to change in terms of care and caring to enable greater gender equality, generally, but also in the context of British South Asian communities specifically. 


\section{Fatherhood}

One area in which care in men's lives has been considered in more depth is fatherhood. Being a father now stands as an integral part of the male caring role and one that requires a gendered analysis (Doucet 2004; 2006; Lewis and Lamb, 2007). There is a substantive body of research which indicates that contemporary fatherhood is multifaceted and enacted in diverse ways (for example Doucet and Lee, 2014; Marsiglio, Day and Lamb, 2000). Wider social changes have meant that whilst diverse, contemporary conceptions of fatherhood have been redefined with an expectation for men to take a more active role in childcare (Hauari and Hollingworth, 2008; Lewis and Lamb, 2007). Yet research has also suggested that fatherhood and men's wider caring activities continue to be structured around normative constructions of masculinity (Doucet, 2006; Reynolds, 2013). In this way, practices of care by men can be restricted; bounded and surveyed through normative and hegemonic constructions of masculinity, curtailing actions deemed too feminine for men to engage in, even for men that take the role of stay at home dads (Doucet, 2004; 2006; Reynolds, 2013). Despite the limited focus on ethnicity, these studies are expanding to look at the diverse range and shifting nature of fatherhood within contemporary family forms (Doucet and Lee, 2014). In the British context, research by Salway, Chowbey and Clarke (2009) and Hauari and Hollingworth (2009), provides some insight into the dynamics of ethnicity, race and religion on fathering in contemporary families.

\section{Other forms of care}

In order to understand how British South Asian men care, it is important to go beyond viewing care solely in relation to fatherhood. The intersection of ethnicity, culture and religion is relevant here, and the wider context of familial relationships within South Asian families. Nijjar (2012) discuses some of the difficulties in maintaining caring relationships in line with expectations and generational differences within South Asian families. Research has also suggested that for some minority ethnic communities, for example British South Asian, there is a greater emphasis, involvement and reliance on families to provide care themselves rather than seek support from other agencies (in relation to dementia, see Lawrence, Murray, Samsi and Banerjee, 2008). This has implications for practices of care within families. Indeed, Maynard, Afshar, Franks and Wray.'s (2008) research on older migrant women in Britain highlights differing cultural ideas of successful ageing; suggesting '[a]t a time when it is common, in some quarters, for people to bemoan the breakdown of family ties, this 
research indicates that interdependence and close contact between family members is both expected and the norm for many' (p.94). Notions of interdependence, obligation and reciprocity between family relations emerge as important in the context of care and caring for British Asian men, as they are not just fathers, but also sons, grandsons, uncles and nephews, all of which matter in shaping masculinities.

\section{Men and masculinity}

Research on masculinity further complicates the discussion of care, parenting and fatherhood. Early works on masculinity such as Connell (1995) and Mac an Ghaill (1994) highlighted the dynamic, contextual and relational nature of masculinities. In this way,

[m] asculinity is not a fixed entity embedded in the body or personality traits of individuals. Masculinities are configurations of practice that are accomplished in social action and therefore, can differ according to the gender relations in a particular social setting (Connell and Messerschmidt, 2005, p.836).

Masculinities can also be understood as performative processes that are played out by individuals within social interactions, so that 'being a man' becomes a performance of recognised and common-sense attributes of masculinity (Connell, 2000; Hopkins, 2006) and '...cannot simply be equated with biological sex' (Mac an Ghaill and Haywood, 2007, p.39). Yet in terms of normative ascriptions of masculinity, it is the notion of hegemonic masculinity that has received extensive attention. Connell and Messerschmidt (2005, p.832) assert that hegemonic masculinities was

...not assumed to be normal in the statistical sense; only a minority of men might enact it. But it was certainly normative. It embodied the currently most honoured way of being a man, it required all other men to position themselves in relation to it, and it ideologically legitimated the global subordination of women to men.

Hegemonic masculinities are relational to subordinate and marginalised forms of masculinity. As Connell (1995, p.81) states ' $[\mathrm{m}]$ arginalization is always relative to the authorization of the hegemonic masculinity of the dominant group'. This questions then how far it is possible for Asian men to aspire to or be aligned to hegemonic or normative notions of masculinity (Kalra, 2009; Gill, 2014).

Within the body of work around masculinities, there are some useful contributions which have sought to understand the ways in which masculinity is differentiated by race and ethnicity, and in the context of Asian masculinity, research which illustrates the lived 
experiences of masculinity for Asian men (and particularly Muslim) in the British context (see for example, Mac an Ghaill, 2004; Alexander, 2000; Hopkins, 2006; Archer, 2001; Kalra, 2009; Britton, 2018). Mac an Ghaill's (1994) research on masculinities and schooling examined the interrelationship and intersection between class, ethnicity and gender in the construction of masculinities, including Asian. This drew attention to the institution of secondary education in the production, construction and organisation of masculinities and masculine 'types'. Alexander's (2000) ethnographic research with young Bengali men sought to disrupt negative pathologies (of criminality and religious fundamentalism) surrounding Asian men, whilst Archer (2001) and Hopkins (2006) highlighted the ways in which religion is used to inform male behaviour. These are useful in helping to disrupt stereotypes of Asian men as either effeminate or hyper-masculine. Kalra's (2009) theoretical contribution emphasised the importance of viewing South Asian masculinities in a postcolonial framework, and not simply in the context of post war migration; whilst also reiterating the complexities of theorising and researching Asian masculinities. More recently, Britton (2018) has published research which also seeks to challenge negative pathologies of Muslim men in particular. Focussing on the under-researched area of 'personal life' (including a discussion of care) in Muslim men's everyday lives and drawing on empirical research data with Muslim men in Rotherham, England, Britton (2018) points to

...the emergence of new masculine subject positions that are adjusting to a changing gender order and raise important questions about the extent to which Muslim men's involvement in caring facilitates greater gender equality. They do so by casting light on dynamic gender and generational relations in Muslim families, providing evidence of Muslim men's changing involvement in caring as part of familial responsibilities (p.18).

Combined, whilst in the main these studies do not focus specifically on care and caring, they nevertheless provide a framework for considering the production and performance of British Asian masculinities.

\section{Method}

The research sought to capture the 'everyday' experiences, intimacies and relationships of care and caring amongst British Asian men in northern England. The participants were both receivers and givers of care, and as Philip et al (2013, p.3) discuss, the findings consider care '... in terms of caring for, with and about others'. The research was not intended to provide a 
representative or generalised picture of British Asian men's experiences of care and caring but rather gain a rich and detailed understanding of care in the context of Asian men's lived experiences. As such, qualitative methods of in-depth semi structured interviews were conducted with a sample of British Asian men from the North of England, with the aim of producing rich narratives. This approach was informed by feminist research methods which foreground 'empathy, rapport and reciprocity' (Doucet and Mauthner, 2008, p.333), with participants defining their own understandings of care. As an Asian male researcher, with personal experiences of care and caring for my (Punjabi speaking) parents from an early age, I was active in this process and the construction of data. The interviews took place in locations determined by the participants, usually their places of work.

The participants were accessed via 'snowball' sampling and purposive sampling, drawn from the researchers existing networks within the voluntary and public sector. Ten of the participants narratives are utilised here, and these participants were aged between their midthirties to early-fifties. Seven were parents and all had some, past or present, responsibility of looking after their own parents and/or grandparents (either as main carers or having care responsibilities shared with other siblings or spouses). The interviews for this article took place during the period of June 2015 to July 2016. All participants were British born, with the exception of one, and participants were from Sikh and Muslim backgrounds. All held professional occupations or ran their own businesses. Further details about the participants have not been provided so as not to compromise their anonymity.

The research followed ethical guidelines for social research regarding consent, participation and confidentiality and was subject to scrutiny through the University school research ethics panel. All interviews were anonymised and pseudonyms were given to the participants. The interviews were conducted by the researcher and transcribed verbatim, which is important for reliability (Silverman, 2011). Thematic analysis of the interview data was undertaken by the researcher whereby the transcripts were labelled and organised into themes. The following themes are discussed here: community and cultural expectations; taking care of money; responsibility, respect and duty; reciprocity and giving something back; and being close by. 


\section{Findings: British Asian men's narratives of care}

\section{Community and cultural expectations}

Caring responsibilities were a central feature in all of the participants' lives. As in Britton's (2018, p.9) research with Muslim men, '[c]aring roles and responsibilities and affective ties are a notable, consistent feature of men's accounts'. For those who were fathers, this included care for their children but more widely related to the sense of obligation they had in relation to caring for their parents. Black feminist literature has highlighted the ways in which cultural practices such as izzat play an important role in the surveillance and control of Asian women lives (Wilson, 1978; Brah, 1996), yet whilst clearly operating within a different gender framework, there are also cultural expectations which impact on men and care, and the ways in which care is performed.

'I would like to look after my parents, my mum and dad, they (within the religion) see it as a high regard, but if I was saying that I was being the carer and I solely stayed at home to look after my parents, it would obviously be looked down at, not down at, but it will be seen as that I'm not really doing anything meaningful (my emphasis). Whereas if I was a woman, or, I don't know they would be more towards a woman being a carer... so if I was to come home and tell my wife to start working... and I'm going to look after the home, there is no doubt that people are going to say "what's he doing?!"... People from our background think it should be the women who should be doing that'. (Anwar)

Here Anwar recognises that care is valued less than other forms of labour outside the home. He attributes this to the wider Pakistani community, however the devaluing of care and care work is not limited to Asian communities but more widely seen across western societies (Lynch, 2009) resulting in significant and well documented gendered implications in terms of economics, status and opportunity (Lynch and Lyons, 2009). Whilst Anwar is a Muslim male, his comments are similar to those in Hall's (2002) research with young Sikhs in Leeds, whereby private and public spaces were culturally differentiated, with the home being the 'Indian' space in which gendered cultural practices were adhered to. Anwar and other participants, both Muslim and Sikh, highlighted the ways in which family and friends reinforce traditional gender roles, and this is the case in relation to notions of care. As Hall (2002, p.173) argues ' $[t]$ he watchful gaze of cousin, aunts and family friends polices the boundaries of proper gender relations in the cultural field'. This has implications in relation to families and care, as Hall (2002: 178) also notes ' .... the emotional and communal pressure to respect one's elders, protect family honour, and submit to what is best for the 
family as a whole continues to keep families together, for the most part, as a solid supportive social unit'. Such a family unit could provide a context for care which is beneficial to the state, those being cared for and about, and for those caring. However, this has clear gendered implications, particularly in terms of izzat (Wilson, 1978). Indeed, the narratives emerging from the participants in this research highlight that the desire to care, to 'be there' can be both positive and empowering whilst also difficult and stressful.

More recent research by Mehrotra (2016) on marriage amongst middle class South Asian women in the U.S. shows the continued presence of gendered cultural expectations relating to marriageability through a 'cultural script' that shape ideas of ideal womanhood (Mehrotra, 2016, p.351). Drawing on the work of Appiah (1994), Mehrotra notes that '[c]entral to Appiah's framework here is the idea that we construct ourselves from a "tool kit" made available by culture and society, and that scripts become a way of "coming into being" for members of shared identity groups' (p.357). In some ways, there is evidence of such a 'cultural script' amongst the British Asian men in this research, and ideal manhood is informed by notions of responsibility towards parents and their care (but not necessarily performed by them as males, rather this enactment of duty is made possible for the majority through heterosexual marriage and the aforementioned 'cultural script' with an 'ideal' womanhood vis a vis 'ideal' manhood within British South Asian families). Again, this points to the gendered nature of care and also the importance of rebalancing care for gender equality, within specific community contexts.

For Anwar, there is a contradiction between faith and cultural beliefs held within community and kin. However, interpretations of faith inform constructions of masculinity and ways of doing gender in everyday lived experiences (see also Hopkins, 2006, for a discussion of young Muslim men's negotiation of Islam in discussions of gender equality). There is recognition of the differing types of 'ideal' masculinity (Gill, 2014), yet these can be contradictory and offer status within differing contexts, for example within the mosque or with peers. There was also a belief that men do need to be responsible for the family, but this did not mean they shed the responsibility of work. Indeed, the participants were aware of rigid assumptions around gender roles, yet they were also prepared to challenge them and take the necessary steps to care for their parents. Structural and interpersonal factors that impact on first generation migrants can and do influence such decisions (including elders experiences of racism, English language skills, lack of awareness of services or a perceived 
insensitivity to cultural/religious sensibilities amongst practitioners, see for example Age UK, 2012; Ahmad and Bradby, 2007). However, this is also about the participants having a sense of duty and responsibility to care for their parents, linked to the aforementioned 'cultural script'. Britton $(2018$, p.9) also notes that such 'culturally situated ideas of how to be a good son' inform Muslim men's family relationships and enactments of care. Shabbir looked after his father in his later years and continues to have a central role in caring for his mother:

'I was taking care of my dad's medication or anything like that. He had a nebulizer at home, so when he needed that and I was at home, I would be putting the medication in that, at the time any other medication he needed to take, I'd go to the chemist and pick it up. Like I did today, I've got my mum's medication in my pocket now. I do it now for my mother as well. Because I'm the only person that lives with my mum, apart from my younger sister it's me, man of the house there now'. (Shabbir)

For Shabbir, flexibility within his employment, as well as support from other siblings enabled him to combine caring and paid work. Shabbir was critical of men who expected their partners to play a substantial role in caring for their in-laws. This not only challenges gendered expectations of male and female roles, but also reflects alternative Asian masculinities. Ajaz, also recounted spending considerable time caring for his mother with support from his wife, and indeed gave up paid employment to provide palliative care to his mum.

'We had the option of Mum to be looked after nurses, Mum had breast cancer... I looked at it as being fortunate to have been there to look after my mum, to have been there to look after her. I didn't look upon it as a being a burden... I've had many a night where I've stayed up all night, continuously for weeks sometimes. Between me and my wife, we kept shifts; I slept on a mattress next to her. I don't think I trusted that care from anyone else, somebody else to come in and do that...But at the time I didn't feel like I was doing anything that was extraordinary and different. And even though you have various organisations out there to help you, I was offered help; I still felt that I needed to be there'. (Ajaz)

Ajaz's story of care shows the possibility for British Asian men to shift and challenge orthodoxies and assumed gendered behaviour in relation to notion of care. Here, caring in the home was prioritised over paid work outside the home, and the narrative told gives an important insight into an alternative performance of British Asian masculinity, which showcases love, emotion and commitment. Britton $(2018$, p.9) also describes how the Muslim men in her research made employment choices informed by their '[a]ffective ties and 
associated caring responsibilities to family members'. Utilising Elliott (2016, p.256), it can be argued that ' $[\mathrm{t}]$ hese nurturing, caring identities constitute a form of men's engagement in gender equality and have the potential to positively change both men and gender'. In Ajaz's emotional recollection of his last days with his mum, he describes his care giving as being both a privilege and an opportunity, and rather than seeing this as a burden, something which he valued positively. This narrative also featured in other participants stories of care to provide an important counter narrative to dominant negative depictions of British South Asian men as patriarchal and fixed (Kalra, 2009). Such performances of masculinity '...embrace the affective, relational, emotional, and inter-dependent qualities of care identified by feminist theorists of care' (Elliott, 2016: 252). Yet it also shows how care in this context is structured and supported within a normative heterosexual relationship; with Ajaz's partner also playing an important role in providing care and supporting him. These narratives of care were powerful and emotive and highlight how care is fundamental in shaping their everyday lives. They further suggest the possibility for more caring masculinities (Elliott, 2016) framed within the intersection of faith, culture and ethnicity..

\section{Taking care of money}

It is evident that masculinities have the potential to be transformed through care and care practices (Elliott 2016), although earlier studies have suggested that caring activities in the home (usually around fatherhood) are structured around normative ascriptions of masculinity (Doucet, 2004; Reynolds, 2013). Duleep's comments reflect this complexity:

'Care is a lot of things actually, it means care for children, care for your family, caring for, even financial responsibility, that's a part of caring, because trying to sort out your financial situation means that you can now put more aim and responsibility into your children, you can put more emphasis into looking after them. So caring means looking after the whole family, I see it as one big unit. You know the wife, kids, you know making that fine as well, and you know we live with our mum, so taking care of her as well....' (Duleep)

Duleep endorses care as an aspect of his everyday family life, whilst also asserting taking financial responsibility as a part of the caring role. Managing financially reflects one ways in which Duleep's caring relates to normative and hegemonic ascriptions of masculinity (see Salway et al, 2009) and this was seen as part of his duty and responsibility. At the same time, he also demonstrates a responsibility for care towards his mother who lives with him. With shifting structures of family life, Doucet's (2004) work on stay at home fathers also points to 
the continued importance that paid employment holds to men's identities. Duleep is not a stay at home dad, but plays an active role in caring for his children as expected in contemporary family forms (see Salway et al., 2009; Hauari and Hollingworth, 2009). Despite more egalitarian family structures, research by Hauari and Hollingworth (2009) found that Pakistani and Black African parents tended to hold more 'traditional' ideas of parental roles within the family, with fathers playing a key role of providing the financial security (see also Hopkins, 2006, in relation to young Muslim men). There was variation within families, whereby mothers expected to and did make financial contributions, however families across ethnic groups felt fathers held the responsibility for protection of the family unit. This suggests that whilst there is evidence of diversity, there has been a continued emphasis on men having particular roles and responsibilities within families, as a father or as sons. Despite Duleep's comments earlier, it could not be said that the participants, including Duleep, endorsed a rigid division of labour or even held a gendered expectation of care, yet they did highlight the difficulty in combining significant caring responsibilities with the traditional role of 'breadwinner.'

\section{Responsibility, respect and duty}

For the participants in this research, care was conceptualised as a responsibility and duty, but also an important part of their everyday lives. When describing care, a sense of duty emerged in participants stories. These were structured around responsibilities that other family members also have, yet a sense of duty was also strongly entrenched in notions of love and compassion:

'I think for me, I don't think about being cared for, I think about caring for others...I think more so for my dad, for example, that feels like it's a duty for me to do, as well as the love and compassion, I need to put my fair share in...' (Amjad).

Sajid develops this further, to consider the ways in which caring responsibilities are enacted through his care for both his elderly parents and his older brother:

'Care is about responsibility. I care for my parents, they're elderly. My mum's not well, I need to be there, I need to be there so she knows that somebody's looking over her...Sometimes my mother worries, where's my brother, if he's gone out for a walk. She gets stressed. I say, 'Look he's ok; he's gone for a walk, he's somewhere so don't worry". Anxiety it affects a lot of people... so I use the word reassurance, care is about reassurance, it's about respect, it's about understanding and sometimes when you're 
caring for people it isn't just a physical thing, it's an emotional thing, but also you have to reassure people. "It's ok, your blood pressure's high, but it's ok"... just checking in on things. We act as doctors, we act as nurses, we have to care in different capacities, as siblings, we have to develop that knowledge as well.'(Sajid)

Sajid's comments convey an understanding of his mother's feelings and emotions, providing reassurance and meeting her needs. This response is subjective and sensitive, reflecting the dynamic and fluid ways in which masculinities have shifted to endorse new ways of being a man, and emergent caring masculinities (Elliott, 2016; Ruby and Scholz, 2018). These practices have not always been considered masculine (Connell, 1995, Connell and Messerschmidt, 2005). Sajid's comments could also been seen to reflect the ways in which masculinity intersects with race, ethnicity, gender and faith within a postcolonial context. Here care and caring for his mother, brother and the family can also be understood as a form of resistance and protection from racism and discriminatory practices (see Reynolds, 2013 for a discussion around this and Black men's care work within Black communities) and reflect the importance of looking at racialisation as lived out by South Asian men in their everyday and personal social lives (Britton, 2018).

\section{Reciprocity - giving something back}

For Sajid and other participants, it is evident that siblings are part of the care landscape, whilst sibling order, as well as gender, informs how 'responsible' a family member should be. In the stories of care here, being the eldest son is of particular importance in how much responsibility and obligation you have towards care. These relationships are also about reciprocity, about giving parents something back. Care is not constructed as rigid and hierarchical; rather it is something dynamic and changing, shifting responsibilities with siblings and the wider family depending on context and situation. Caring relations are also about receiving care in different ways. As research by Maynard et al. (2008: 94) suggests, care is not one-sided, with older women playing an important role in providing care as well as receiving it.

A strong sense of obligation, duty and reciprocity leads us to talk of the moral economy of kin, with older women playing a pivotal role, through child care and doing other domestic tasks, in allowing other family members to work. In fact, being a grandmother was a significant dimension in participants' sense of self and was seen as an enjoyable and rewarding experience in its own right. 
Salway et al.'s (2009) work also shows that whilst there is diversity in terms of grandparents' involvement in parenting, they continue to play important role in family life. Many of the participants conveyed a need to give something back to their parents who have made sacrifices for them. Others such as Jagdeep talked about important role their parents played in supporting them with care for grandchildren:

'And Mum and Dad they live next door, it is, they're a massive help. My mum's amazing to be honest; she picks them up and drops them off'. (Jagdeep)

Such reciprocity is an important feature of caring relationships, yet it also one that is complex as the participants also discussed care and caring as a source of guilt and anxiety.

(As the oldest son) 'So really my job should have been to stay at home. I do everything at the house... it all lands on me, the whole house where Mum and Dad live. I've got a brother and sister that turn up as well, but really I should be the one who's there. But the way things are, I got married and moved out, I didn't move far, I moved out, I'm not in the family home anymore... that to me is almost, like the guilt and pressure. So I think if anything happens I think I'd go home... in an ideal world, you'd have a house that everyone lived next to you...' (Avtar)

The sense of responsibility and obligation has a massive emotional bearing on Avtar. Whilst there is clearly agency and a negotiation of responsibilities and obligation, for Avtar there was an expectation to live in a multi-generational family house. A number of participants talked about the need to care being a burden and the anxiety of meeting care obligations alongside other demands, such as employment or as in Avtar's case leaving the family home to start his own family. Parveen et al.'s (2013) work on South Asian and White-British care givers and the influences of familism, on coping, moods and motivations, also found that failing to fulfil obligations caused distress for South Asian care givers.

However, at the same time the participants talked about care as unconditional and spontaneous. These narratives further contribute towards a notion of 'caring masculinities' (Elliott, 2016; Ruby and Scholz, 2018).

'It's like a feeling, innit, you care for people. You start from something simple like that and it evolves.... You don't even think of that as care really, it's something you've got to do'. (Ajaz) 
A discussion around locality featured in the comments of many of the participants. For the majority, close proximity to family networks was important to enable them to care and enact the appropriate role. Most described living with their parents or very close by:

'The majority of us come from large families, within those family structures; it was easier to look after one and another. You all lived locally; you all lived in the same area. You know it was easier to look after your uncles and aunts. It wasn't just the case of your immediate family, but you had a big family. But you know even within that family you had your local people that live near you, that fit in that category'. (Ajaz)

'Obviously, Dad's just down the road from us guys, with my brothers living in the family house. I mean that was definitely something that was, when we were first thinking about moving out, getting our own house, that was on top of the list: how close are we to Mum and Dad. I mean at the time, options were open to go pretty much anywhere in [city], but it was like we need to be a certain distance. Like my dad is obviously elderly, he's not well; he's not been well for a good few years, so definitely easier living locally.' (Amjad)

In Amjad's and Ajaz's narratives, doing care was enabled by living in close proximity to family. For my participants this was not specific to any religious group, rather all of the participants' lived close by, or even in the same household to their parents, and/or elderly grandparents. Indeed, these stories of wanting to be close to kin in order to be able to 'care' (and receive care) was an important commonality across the different ethnic and religious backgrounds. It is significant that whilst there has been increasing emphasis on difference and differentiation within British South Asian communities since the late 1980s, this research suggests that the desire to want to 'be there' and provide care and support for family members, is a shared narrative amongst British South Asian men and their stories of care. This desire to care and the performance of care, further supports the notion of emerging caring masculinities (Elliott, 2016; Ruby and Scholz, 2018) in the everyday lived experiences of British South Asian men (see also Britton 2018). Participants also talked about the importance of living in communities that were well-networked (with places of worship, community groups and ethnic amenities in close proximity) as ideal for their parents, although not always ideal for them. Many of the participants who were in professional occupations were in a position to move to more affluent areas if desired. However a choice was made to remain in the same location as family and kin and the wider familiar community. These localities of community ensured and encouraged caring relationships and the participants also played an active role of making community through caring activities. 
Community then can play a part in encouraging familial relations of care and enabling the development of caring masculinities.

\section{Conclusion}

This article has considered how care features in the lives and experiences of British Asian men. Drawing on qualitative research conducted in the north of England with men from Sikh and Muslim backgrounds, the research findings discussed highlight the centrality of care to British Asian men's lives; not just as fathers but also as brothers, cousins, husbands and sons. The research area is significantly under-researched, yet of increasing significance given the demographic changes in the UK and also increasing questions nationally surrounding how we should care and who should provide (and fund) care, particularly for an ageing population. Theoretically, there is a now an emerging body of literature relating to masculinity and care, although this is underdeveloped in terms of ethnicity, and especially in the context of the personal lives of British South Asian men (with Britton, 2018, as a notable and important exception). Feminist literature has emphasised the continued gendered landscape of care, and is also paramount in drawing attention to the ways in which care has been devalued as a form of labour. It is also apparent that an analysis of masculinity and care is necessary in order to examine ways in which 'caring masculinities' (Elliott, 2016) have the potential to be transformative in terms of gender relations.

Whilst the participant's individual stories of care are diverse, there are common themes which highlight that care is central in the lives of British South Asian men (see also Britton , 2018). The participants place value on 'being there' to provide care and support to family, particularly parents, and see this both as a duty but also a privilege which can be enriching, emotional and rewarding. Following Maynard et al.'s (2008) research with older women; there is also evidence of the importance of interdependence, obligation and reciprocity between family relations in the lives of British Asian men. It is also significant that this is a commonality between those from different religious backgrounds, pointing to an inclusive notion of British 'Asian' identity, as opposed to an understanding of Asian ethnicity as one fractured through ethnic and religious differences.

Whilst providing an important insight into the ways in which British Asian men engage in care, this research also points to an alternative construction of Asian masculinities, one which embraces care and compassion, seeks to engage and challenge gendered practices in familial 
and community contexts, and ultimately points to a more hopeful construction of contemporary British Asian masculinities. It is a shift from the dominant representations of Asian men as fanatics, domineering, simultaneously being effeminate and hyper masculine bodies (Kalra 2009; Gill 2014). The research findings highlight that for British Asian men, normative masculinities are framed within the intersection of gender, religion, ethnicity, race/racialisation and location, with a commitment to family ties and care being centralised in a way in which hegemonic masculinities has not historically incorporated. This may suggest that doing care within the context of family and community is more culturally acceptable for British Asian men than for men from different ethnic/cultural backgrounds. The 'cultural script' (Mehrotra, 2016) which informs British Asian men's performance of masculinities is one which places value on care and commitment to family, and is in some ways reflective of what masculinity theorists identify as 'caring masculinities' (Elliott, 2016). The emergence of caring masculinities is recognised as important for progressing and transforming gender relations, and what is significant is that the participants narratives here (and in Britton's 2018 research), challenge populist and pathologising constructions of Asian masculinity. This is not to underplay the very real ways in which a gendered 'cultural script' and patriarchal practices such as izzat, have particular implications for women in British South Asian communities (Wilson, 1978; Brah, 1996). Indeed this research does not claim to speak for all British Asian men, and it is important to remember that as with any qualitative research, the findings are a product co-constructed between myself as an Asian male researcher and the participants.

In terms of enhancing our understanding of contemporary British Asian masculinities, this research also reflects the complex ways in which race, ethnicity and gender play out to construct a particular way of 'being a man' where notions of care, compassion and reciprocity are important. These are not necessarily evident when we think of normative or hegemonic constructions of masculinities. Indeed, care and caring cannot simply be assumed to be practices that are attributed to subordinate or effeminised masculinities, but rather can and do reflect normative and ideal masculinities within the narratives presented. Whilst the suggestion is that men in caring roles struggle to shift from traditional or gendered positions, normative masculinities need to been considered as complex and dynamic, whereby men have the space to provide care in a range of different ways. At the same time, the processes of racialisation that have subordinated Asian communities within the post-colonial context can also be seen to impact on Asian men and their desire to 'be there'. 


\section{Acknowledgements}

I would like to thank the men who gave up their time to talk about their experiences of care. Thanks also to the reviewers for providing constructive feedback in the development of this article.

\section{References}

Age UK (2016). Briefing: Health and Care of Older People in England 2016. Retrieved from Age UK website:http://www.ageuk.org.uk/Documents/EN-GB/Forprofessionals/Research/The_Health_and_Care_of_Older_People_in_England_2016.pdf?dtrk $=$ true

Age UK (2012). 'Fit as a Fiddle': Engaging faith and BME communities in activities for wellbeing. Retrieved from Age UK website:https://www.ageuk.org.uk/Documents/ENGB/FaithGood\%20Practice\%20GuideWEB.pdf?dtrk=true

Ahmad, W. I., \& Bradby, H. (2007). Locating ethnicity and health: exploring concepts and contexts. , Sociology of Health \& Illness 29(6), 795-810.

Archer, L. (2001). 'Muslim brothers, Black lads, traditional Asians': British Muslim young men's construction of race, religion and masculinity. Feminism and Psychology 11(1), 79105.

Bhattacharyya, G. (2008). Dangerous Brown Men: Exploiting Sex, Violence and Feminism in the War on Terror. London: Zed Books.

Brah, A. (1996). Cartographies of Diaspora: Contesting Identities. London: Routledge.

Britton, J. (2018). Muslim Men, Racialised Masculinities and Personal Life. Sociology. Advance online publication. [DOI 10.1177/0038038517749780]

Cockbain, E. (2013). Grooming and the 'Asian sex gang predator': the construction of a racial crime threat. Race \& Class, 54(4), 22-32.

Connell, R.W. (1995). Masculinities. Cambridge: Polity Press:

Connell, R.W. (2000). The Men and the Boys. Cambridge: Polity Press

Connell, R. W., \& Messerschmidt, J. W. (2005). Hegemonic masculinity: Rethinking the concept. Gender \& Society, 19(6), 829-859.

Doucet, A. (2004). "It's almost like I have a job, but I don't get paid": Fathers at home reconfiguring work, care, and masculinity. Fathering, 2(3), 277-303.

Doucet, A. (2006). 'Estrogen-filled worlds': Fathers as primary caregivers and embodiment. The Sociological Review, 54(4), 696-716. 
Doucet, A. and Mauthner, N. (2008). 'Qualitative Interviewing and Feminist Research'. In P. Alasuutari, L. Bickman, \& J. Brannen, (Eds.), The SAGE Handbook of Social Research Methods (pp. 328-343). London: Sage Publications.

Doucet, A. \& Lee, R. (2014). Fathering, feminism (s), gender, and sexualities: Connections, tensions, and new pathways. Journal of Family Theory \& Review, 6(4), 355-373

Elliott, K. (2016). Caring Masculinities: Theorizing an Emerging Concept. Men and Masculinities, 19 (3), 240-259.

Gill, S. S. (2014). 'So people know I'm a Sikh': Narratives of Sikh masculinities in contemporary Britain. Culture and Religion, 15(3), 334-353.

Haywood, C. \& Mac an Ghaill M. (2012). 'What's next for masculinity?' Reflexive directions for theory and research on masculinity and education. Gender and Education, 24(6), 577-592.

Hall, K. (2002). Lives in Translation: Sikh Youth as British Citizens. Pennsylvania: University of Pennsylvania Press.

Hall, S. (1992). New ethnicities. In J. Donald \& A. Rattansi (Eds.), Race, Culture and Difference (pp. 252-260). London: Sage Publications.

Hauari, H. and Hollingworth, K. (2009). Understanding Fathering. Masculinity, Diversity and Change. Retrieved from Joseph Rowntree Foundation website:

https://www.jrf.org.uk/report/understanding-fathering-masculinity-diversity-and-change

Hoff, A. (2015). Current and future challenges of family care in the UK: future of an ageing population. Evidence review: March 2015. Retrieved from Foresight, Government Office for Science website:http://dera.ioe.ac.uk/24148/1/gs-15-18-future-ageing-family-care-er09.pdf

Hopkins, P. (2006) Youthful Muslim masculinities: gender and generational relations. Transactions of the Institute of British Geographers 31(3), 337-352.

Kalra, V. S. (2009). Between emasculation and hypermasculinity: theorizing British South Asian masculinities. South Asian Popular Culture, 7(2), 113-125.

Lawrence, V., Murray, J., Samsi, K., \& Banerjee, S. (2008). Attitudes and support needs of Black Caribbean, South Asian and White British carers of people with dementia in the UK. The British Journal of Psychiatry, 193(3), 240-246.

Lewis, C., \& Lamb, M. E. (2007). Understanding Fatherhood: A Review of Recent Research. Retrieved from Joseph Rowntree Foundation website: https://www.jrf.org.uk/sites/default/files/jrf/migrated/files/understanding-fatherhood.pdf

Lieversley, N. (2010). The Future Ageing of the Ethnic Minority Population of England and Wales. Retrieved from Runnymede Trust website:

https://www.runnymedetrust.org/uploads/publications/pdfs/TheFutureAgeingOfTheEthnicMi norityPopulation-ForWebJuly2010.pdf 
Lynch, K. (2007). Love labour as a distinct and non-commodifiable form of care labour. The Sociological Review, 55(3), 550-570.

Lynch, K. (2009). Affective equality: Who cares? Development, 52(3), 410-415.

Lynch, K., \& Lyons, M. (2009). Love Labouring: Nurturing Rationalities and Relational Identities. In K. Lynch, J. Baker and M. Lyons (Eds) Affective Equality, (pp54-77), Basingstoke: Palgrave Macmillan

Mac an Ghaill, M. A. (1994). The Making of Men: Masculinities, Sexualities and Schooling. Buckingham: Open University Press.

Mac an Ghaill, M. and Haywood, C. (2007) Gender, Culture and Society: Contemporary Femininities and Masculinities. Basingstoke: Palgrave Macmillan.

Marsiglio, W., Day, R. D., \& Lamb, M. E. (2000). Exploring fatherhood diversity: Implications for conceptualizing father involvement. Marriage \& Family Review, 29(4), 269293.

Maynard, M., Afhsar H., Franks, M. and Wray, S. (2008). Women in Later Life: Exploring Race and Ethnicity. Maidenhead: Open University Press

McClintock, A. (1995). Imperial leather: Race, Gender, and Sexuality in the Colonial contest. London: Routledge.

Mehrotra, G. R. (2016). South Asian women and marriage: Experiences of a cultural script. Gender Issues, 33(4), 350-371.

Nijjar, M. K. (2012). Perspectives on Ageing in South Asian Families. York: Joseph Rowntree Foundation. Retrieved from Joseph Rowntree Foundation website: https://www.jrf.org.uk/sites/default/files/jrf/migrated/files/ageing-south-asian-families$\underline{\text { summary.pdf }}$

ONS (2016).Women shoulder the responsibility of 'unpaid work'. Office of National Statistics. Retrieved Online:

https://www.ons.gov.uk/employmentandlabourmarket/peopleinwork/earningsandworkinghou rs/articles/womenshouldertheresponsibilityofunpaidwork/2016-11-10

Parveen, S., Morrison, V., \& Robinson, C. A. (2013). Ethnicity, familism and willingness to care: Important influences on caregiver mood? Aging \& Mental Health, 17(1), 115-124.

Philip, G., Rogers, C., \& Weller, S. (2013). Understanding care and thinking with care. In C. Rogers \& S. Weller (Eds.) Critical Approaches to Care: Understanding Caring Relations, Identities and Cultures (pp.1-12). London: Routledge

Reynolds, T. (2013). 'Men's business'? Black men's caring within black-led community organisations. In C. Rogers \& S. Weller (Eds.) Critical Approaches to Care: Understanding caring relations, identities and cultures. (pp.82-91). London: Routledge. 
Ruby and Scholz (2018). Care, care work and the struggle for a careful world from the perspective of the sociology of masculinities. Österreich Z Soziol, 43 (1), 73-83.

Salway, S., Chowbey, P., \& Clarke, L. (2009). Understanding the experiences of Asian fathers in Britain. York, UK: Joseph Rowntree Foundation. Retrieved from Joseph Rowntree Foundation website: https://www.jrf.org.uk/sites/default/files/jrf/migrated/files/Asian-fathersBritain-full.pdf

Silverman, D. (2011) Interpreting Qualitative Data (4 ${ }^{\text {th }}$ ed.). London: Sage Publications.

Wilson, A. (1978). Finding a Voice, London: Virago 